\title{
CLINICAL DEPARTMENT
}

\section{ACUTE MYELITIS FOLLOWING VARICELLA}

\author{
REPORT OF A CASE * \\ D. C. WHARTON SMITH, II, M.D. \\ BALTIMORE
}

It is believed that almost any of the infectious diseases may attack the central nervous system to produce encephalitis or myelitis. The following is a list of those mentioned: Typhoid fever, typhus fever, erysipelas, malaria, variola, measles, acute rheumatism, severe puerperal infections, scarlatina, influenza, pneumonia, pertussis, dysentery, cholera, gonorrhea, streptococcus and staphylococcus infections. Only one author (Councilman) has in recent years mentioned varicella as a possible cause. The case that I am now reporting bears such a close relationship to an attack of varicella that $I$ consider it of sufficient interest to record.

History.-The patient, R. T., a white boy, 7 years of age, applied for treatment at the dispensary of the Harriet Lane Home, Aug. 17, 1914, complaining of "stiff knees."

Family History.-Unimportant.

Personal History.-The patient was a full term child, following a normal delivery. He was breast fed for eighteen months, and cut his first tooth at seventh month. There was an abscess behind the left ear at the eighth month, which was not serious, and pertussis at 5 years. These were the only two illnesses that he had had, and with these two exceptions, the patient has always been a healthy child.

Present Illness.-Ten weeks before, June 1, 1915, the patient had an attack of varicella, just after his older brother had recovered from a similar one. He had the usual papulovesicular eruption which was very wide-spread.

Eight weeks before, June 14, 1915, or two weeks after the onset of varicella, the patient's temperature began to rise, and his mother noticed that his legs were drawn up. It was further discovered that he was unable to move either of his legs or his left arm. There was also loss of sensation over these parts, which was more marked over the left leg than over the right. This last condition persisted for two weeks, and sensation gradually returned again. His left arm was held over his head, and he would scream with pain if one attempted to pull it down or to straighten out either of the legs.

A few days after the onset of these symptoms, the child suffered with retention of urine and was catheterized twice. This was followed by incontinence of both urine and feces. This incontinence continued for six or seven weeks. On the first application, or eight weeks after the attack, it was found that under ordinary conditions the sphincter control was good; however, the urine could not be long retained.

* Submitted for publication Oct. 8, 1915. 
The patient was admitted to the Harriet Lane Home, August 19, 1914.

Physical Examination.-The child was undernourished but did not look sick. His head, heart, lungs, abdomen and genitalia were apparently normal.

The knees were flexed and the legs could not be entirely straightened. The muscles were soft and perhaps slightly atrophied. Both knee-kicks were hyperactive, the right more so than the left. There was an ankle clonus on both sides, which was better sustained on the right. The muscular strength was good and equal in the arms. The legs were very weak, though they could be moved fairly well voluntarily. Sensations of touch, pain, and temperature were apparently normal. There was some hyperesthesia of both legs.

Of laboratory findings, the von Pirquet skin test was questionably positive, the spinal fluid normal, and the Wassermann negative in both spinal fluid and blood. The eyegrounds were found to be normal.

Sept. 4, 1914, the patient was discharged from the hospital, improved.

Oct. 2, 1914, he returned to the dispensary. He was able to walk slowly and with some difficulty, with both his knees somewhat flexed. The steps were short and the feet were dragged along the floor. He was still suffering with urinary incontinence if there was any delay in reaching the toilet. There was, however, no incontinence of feces.

On physical examination the legs looked thin, as though some atrophy had taken place. The tendon reflexes were still greatly increased. Babinski's test was positive on both sides. There was an ankle clonus present on the right.

Aug. 5, 1915, one year after the first admission, the patient appeared greatly improved and was able to play freely. There was still some definite spasticity noticeable in the lower extremities, best brought out after running or walking rapidly. $\mathrm{He}$ was able to extend his legs normally. The tendon reflexes were hyperactive as before, and the Babinski was positive on both sides. There was no ankle clonus, and no evidence of urinary incontinence except at night, a condition which had existed prior to his illness.

The occurrence of these symptoms indicated unmistakably a definite lesion in the cord. They followed so closely on an infection with varicella that it seems justifiable to consider these two conditions as having a definite relationship, especially as there was an absence of any external condition to which might be assigned an etiologic significance. 